\title{
Recurrent and Invasive Primary Squamous Cell Carcinoma of the Chest Wall: A Case Report
}

\author{
Corona Figueroa Alejandro Angel ${ }^{1 *}$ (1) , García Rodríguez Francisco Mario², \\ Lorenzo Silva José Manuel3, Corona Padilla Alejandro Arnulfo4 (i), Mancera Steiner Carlos², \\ González Chávez Alberto Manuel ${ }^{1}$ (i)
}

\author{
${ }^{1}$ General Surgery Service, Hospital Español de México, México City, México \\ ${ }^{2}$ Oncology Surgery Service, Hospital Español de México, México City, México \\ ${ }^{3}$ Thoracic Surgery Service, Hospital Español de México, México City, México \\ ${ }^{4}$ Plastic Surgery Service, Hospital Español de México, México City, México \\ Email: ${ }^{\star}$ alejandrocoronafigueroa@gmail.com
}

How to cite this paper: Angel, C.F.A., Mario, G.R.F., Manuel, L.S.J., Arnulfo, C.P.A., Carlos, M.S. and Manuel, G.C.A. (2020) Recurrent and Invasive Primary Squamous Cell Carcinoma of the Chest Wall: A Case Report. Surgical Science, 11, 209-215.

https://doi.org/10.4236/ss.2020.118023

Received: June 23, 2020

Accepted: August 17, 2020

Published: August 20, 2020

\section{Copyright $\odot 2020$ by author(s) and} Scientific Research Publishing Inc. This work is licensed under the Creative Commons Attribution International License (CC BY 4.0).

http://creativecommons.org/licenses/by/4.0/

\begin{abstract}
Squamous cell carcinoma is a type of skin cancer with abnormal proliferation of keratinocytes. Its incidence reaches approximately $20 \%$ of cases of non-melanoma skin cancer, which has increased in recent decades due to growth in life expectancy, increased sun exposure, the use of tanning beds and improved detection of this type of tumors. We present a patient who was diagnosed with a squamous cell skin carcinoma in the chest wall, treated initially with surgical resection. A few years recurred in the same place, so the patient received radiotherapy with poor response. Ultimately a new surgical approach was performed with a wide margin resection by a multidisciplinary surgical team. Multidisciplinary management in this type of procedure is important so that the long-term result is optimal for the patient.
\end{abstract}

\section{Keywords}

Squamous Cell Carcinoma, Skin Cancer, Chest Wall Tumor, Oncological Sternectomy

\section{Introduction}

Squamous cell carcinoma is a malignant tumor that originates from the keratinocytes of the epidermis. It is the second most frequent non-melanocytic malignant tumor of the skin. Usually, it appears in areas exposed to the sun (main risk factor), which suffer photodamage, such as the head, trunk, neck, and extremities. It occurs more frequently in men (3:1) as dermatological lesions or gener- 
ally raised, erythematous, and scaly plaques that can be accompanied by itching and bleeding on the surface [1].

Depending on the affected area, squamous cell carcinoma has multiple forms of presentation [2] [3]:

- Bowen's disease: Cutaneous carcinoma in situ.

- Queyrat's erythroplasia: Squamous cell carcinoma that occurs on the penis.

- Keratoacanthoma: A well-differentiated subtype of squamous cell carcinoma that usually appears in areas with significant photo damage.

- Verrucous carcinoma: The tumor grows exophytically, emulating the shape of a cauliflower, which can occur in the oral mucosa, in the ano-genital area (Buschke-Löwenstein disease) or on the sole of the foot (epithelioma cuniculatum).

- Marjolin's ulcer: Squamous cell carcinoma that arises from a chronic scar or from the bed of a burn.

- Lymphoepithelial carcinoma: A very rare, spinous carcinoma subtype with a lymphoid infiltrate reminiscent of a nasopharyngeal carcinoma. It occurs predominantly in the head and neck.

- Other very rare variants: Sarcomatoid squamous cell carcinoma, pseudovascular squamous cell carcinoma, and squamous cell carcinoma with osteoclast-like giant cells.

In the context of squamous cell carcinoma, invasive behavior refers to the growth of the neoplastic cells beyond the layers of the epidermis. Characteristics distinctly associated with invasive behavior that favor recurrence and metastasis are as follows: diameter $2 \mathrm{~cm}$, depth $2 \mathrm{~mm}$, perineural invasion, little differentiation, anatomical site (ears or lips), tumors arising from scars, and immunosuppression [4].

In the case described below, a primary squamous tumor of the thoracoabdominal region exhibited an invasive behavior, which required aggressive and definitive management.

We want to present this case, because its invasive behavior conditioned the performance of an oncological sternectomy, which is extremely rare.

\section{Case Presentation}

Here we present (with the patient's consent) the case of a 65 -year-old male with no comorbidities. He attended a surgical oncology consultation; he had a history of a slowly growing lesion at the xiphisternal joint, which was totally extirpated in 2011. Biopsy of the lesion revealed cutaneous squamous cell carcinoma with negative edges. Six years later, the patient presented a second lesion in the same location.

A cutaneous lesion in the anterior chest wall was observed, characterized by erythematous edges, with greyish coloration and ulcerated patches, and measuring $6 \times 5 \mathrm{~cm}$ in size (Figure 1). The patient received a complete cycle of radiation therapy and five cycles of adjuvant chemotherapy (cisplatin). How- 
ever, the skin lesion did not disappear, multiple punch biopsies confirmed moderately differentiated cutaneous squamous cell carcinoma; therefore, surgical resection was indicated. Surgical treatment was decided with surgical planning for wide resection that includes the abdominal wall in its entirety with resection of the sixth and seventh costal arches, distal third of the sternum, and pleura (Figure 2). Surgical treatment also included the reconstruction of the rib cage with the Stracos system; reconstruction of the abdominal wall with propylene mesh (Figure 3); and an inverse abdominal flap for abdominal wall coverage, umbilical hernioplasty, and creation of a neo-umbilicus (Figure 4).

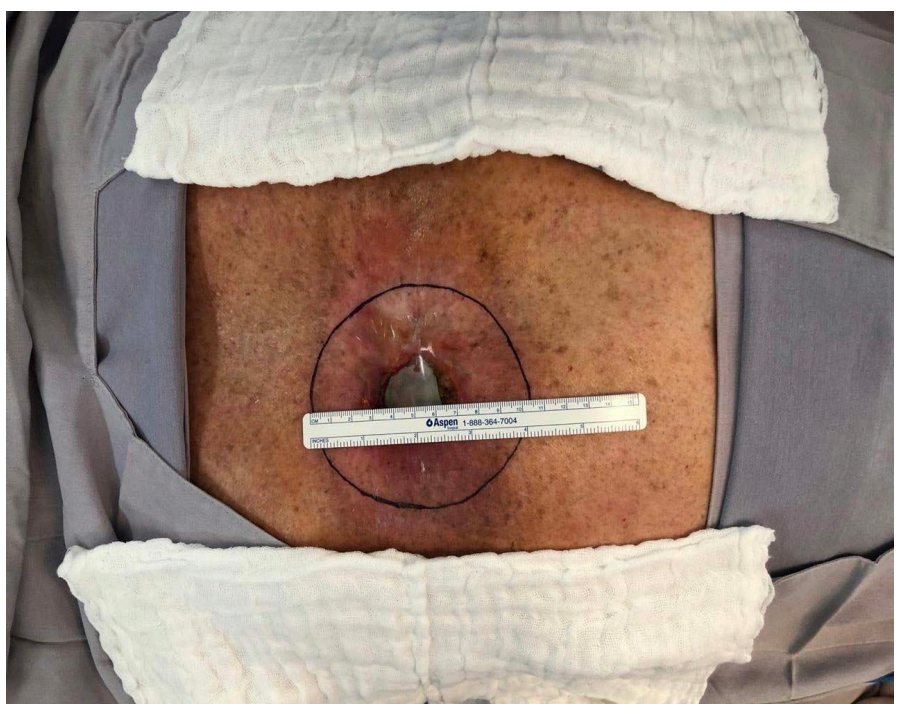

Figure 1. Surgical planning, original lesion with extended margins.

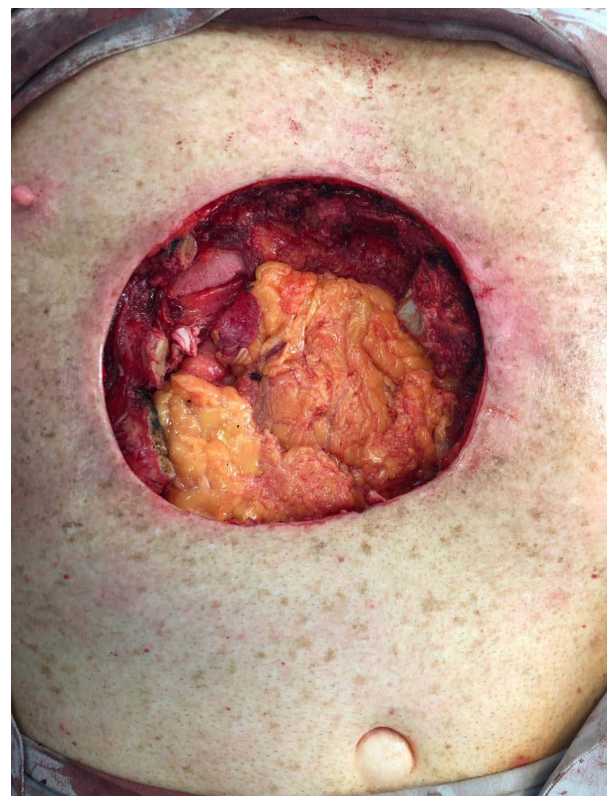

Figure 2. Complete resection of the lesion with extension to the peritoneum and right pleura. 


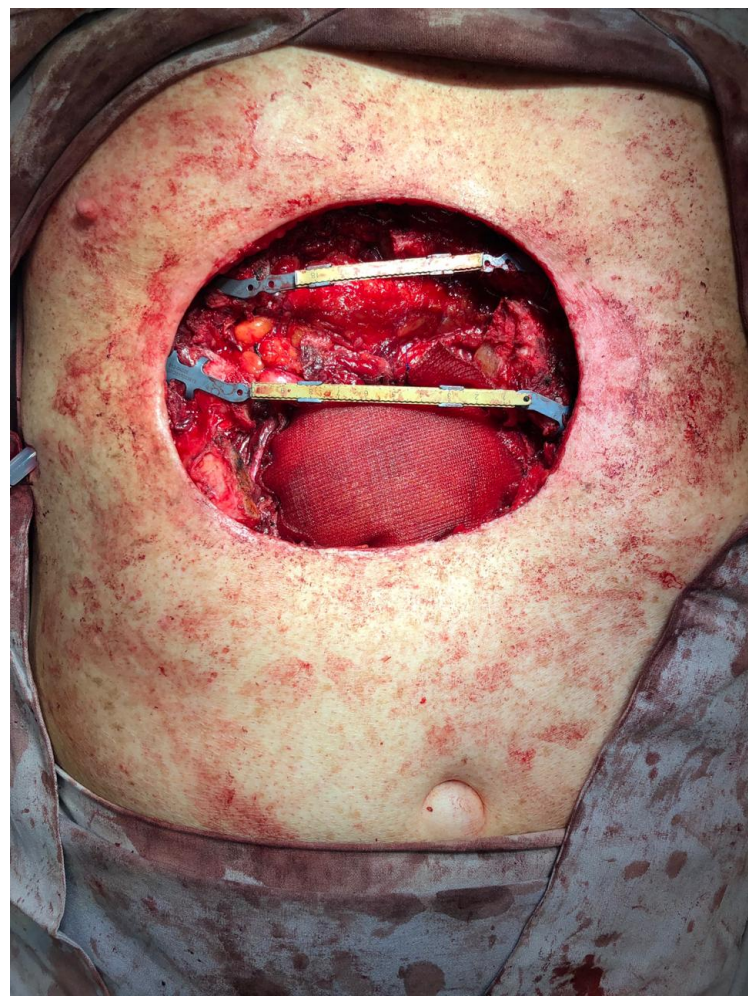

Figure 3. Reconstruction and stabilization of anterior thoracic wall with Stracos system, repair of right pleural and placement of polypropylene mesh.

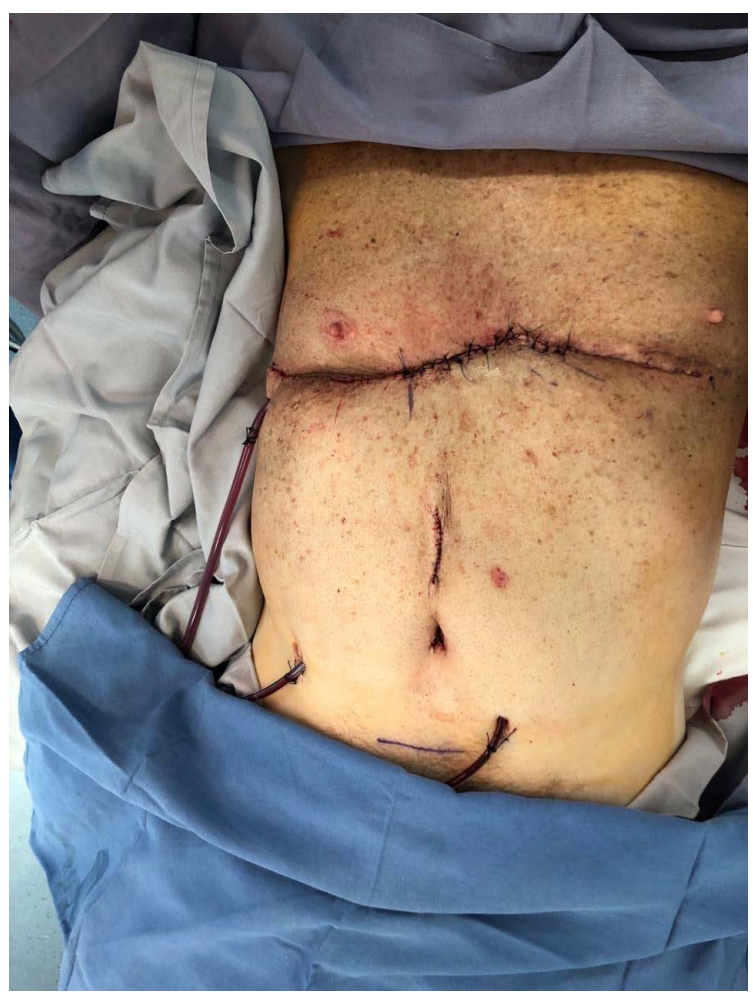

Figure 4. Full coverage of surgical defect with lower abdominal advancement flap. 
The patient has been followed up for approximately 12 months and remains without recurrence of the injury and with an acceptable aesthetic appearance after reconstruction.

\section{Discussion}

When evaluating a tumor on the chest wall, it should be first determined whether the tumor is a primary tumor or an invasive tumor that originates from the adjacent organs, the breast and lung being the most common sources. If the tumor is primary, it may have originated from the bone or soft tissue [5].

The anterior aspect of the thorax, especially towards the midline, is a very rare location for squamous carcinomas. For $95 \%$ of these tumors, early aggressive surgical resection with free margins is usually curative; however, this was not observed in our patient. Therefore, both the location and the recurrence and depth of the invasion make this case a true rarity [6].

The factor that most influences recurrence is incomplete resection of the tumor or positive margins. Although this type of tumor is rarely fatal, its radical treatment can lead to high morbidity and mortality. The literature reports a mortality of $2 \%$ and a metastatic risk of $4 \%$ [7].

Sternectomy is a very rare surgery in oncology and is usually indicated for the treatment of primary chest wall tumors. Sternum resection, even if it is partial, for treatment of skin cancer is very rare [8]. A multidisciplinary team comprising thoracic surgeons, onco-surgeons, plastic surgeons, radio-oncologists, oncologists, and anesthesiologists participated in the resolution of this case. The objectives of the approach included complete resection of the lesion, functional reconstruction of the chest wall that allows recovery of respiratory function as soon as possible, strengthening of the abdominal wall (with synthetic material) to avoid subsequent hernias, and close surveillance to avoid relapses with increased aggressiveness [9] [10].

Medical follow-up is extremely important after treatment for squamous cell carcinoma as up to $80 \%$ and $95 \%$ of recurrences occur in the first 2 and 5 years of surgery, respectively. Various studies indicate that the recurrence rate ranges from $2.2 \%$ to $11 \%$. According to the National Comprehensive Cancer Network (NCCN) guide, in local disease, a follow-up should be done every 3 to 6 months for 2 years, then every 6 to 12 months for up to 5 years, and then annually. In regional disease, a follow-up is recommended every 1 to 3 months for 1 year, then 2 to 4 months for another year, then 4 to 6 months for 3 years, and then every 6 to 12 months indefinitely. Some authors recommend the use of ultrasound every 3 to 6 months to investigate the presence of regional nodes [11] [12] [13].

\section{Conclusion}

Although squamous cell carcinoma is very common, some of these tumors do not behave as anticipated and require aggressive management. It is important to identify the injury and study it properly to be able to stage it and provide the 
correct treatment. Occasionally, to offer the adequate treatment, such as complete resection with negative edges, it is necessary to seek multidisciplinary management so that the long-term result is optimal for the patient.

\section{Conflicts of Interest}

The authors declare no conflicts of interest regarding the publication of this paper.

\section{References}

[1] Waldman, A. and Schmults, C. (2019) Cutaneous Squamous Cell Carcinoma. Hematology/Oncology Clinics, 33, 1-12. https://doi.org/10.1016/j.hoc.2018.08.001

[2] Cassarino, D.S., DeRienzo, D.P. and Barr, R.J. (2006) Cutaneous Squamous Cell Carcinoma: A Comprehensive Clinicopathologic Classification: Part Two. Journal of Cutaneous Pathology, 33, 261-279. https://doi.org/10.1111/j.0303-6987.2006.00516.x

[3] Petter, G. and Haustein, U.F. (2000) Histologic Subtyping and Malignancy Assessment of Cutaneous Squamous Cell Carcinoma. Dermatologic Surgery, 26, 521-530. https://doi.org/10.1046/j.1524-4725.2000.99181.x

[4] Alam, M., Armstrong, A., Baum, C., Bordeaux, J.S., Brown, M., Busam, K.J., et al. (2018) Guidelines of Care for the Management of Cutaneous Squamous Cell Carcinoma. Journal of the American Academy of Dermatology, 78, 560-578. https://doi.org/10.1016/j.jaad.2017.10.007

[5] Kotani, K., Makihara, S. and Tada, R. (2011) Squamous Cell Carcinoma of the Chest Wall in a Patient with Chronic Empyema. Kyobu Geka. The Japanese Journal of Thoracic Surgery, 64, 549-551.

[6] Misiakos, E.P., Damaskou, V., Koumarianou, A., Gouloumi, A.R., Patapis, P., Zavras, N. and Machairas, A. (2017) A Giant Squamous Cell Carcinoma of the Skin of the Thoracic Wall: A Case Report and Review of the Literature. Journal of Medical Case Reports, 11, 1-4. https://doi.org/10.1186/s13256-017-1281-8

[7] Burton, K.A., Ashack, K.A. and Khachemoune, A. (2016) Cutaneous Squamous Cell Carcinoma: A Review of High-Risk and Metastatic Disease. American Journal of Clinical Dermatology, 17, 491-508. https://doi.org/10.1007/s40257-016-0207-3

[8] Pinheiro, V.E.G., Bezerra, B.R., Farias, L.A.B.G., Araujo Filho, I.T.D. and da Fonseca, M.R.S. (2019) Sternectomy for Treating Advanced Non-Melanoma Skin Cancer. Journal of Skin Cancer, 2019. https://doi.org/10.1155/2019/3948782

[9] Schmults, C.D., Karia, P.S., Carter, J.B., Han, J. and Qureshi, A.A. (2013) Factors Predictive of Recurrence and Death from Cutaneous Squamous Cell Carcinoma: A 10-Year, Single-Institution Cohort Study. JAMA Dermatology, 149, 541-547. https://doi.org/10.1001/jamadermatol.2013.2139

[10] Sanna, S., Brandolini, J., Pardolesi, A., Argnani, D., Mengozzi, M., Dell'Amore, A. and Solli, P. (2017) Materials and Techniques in Chest Wall Reconstruction: A Review. Journal of Visualized Surgery, 3. https://doi.org/10.21037/jovs.2017.06.10

[11] Uribe-Bojanini, E., García, Á.M.L., Calfat, G.J., Quiroga, Á.E.S. and Montoya, M.E.M. (2017) Carcinoma escamocelular de la piel de alto riesgo: Definición, diagnóstico y manejo. Med Cutan Iber Lat Am, 45, 8-13.

[12] Iribarren, O., Ramírez, M., Madariaga, J.A., Riveros, Ó., Valdés, C. and Toledo, J. (2018) Carcinoma de células escamosas de piel. Serie de casos. Revista chilena de 
cirugía, 70, 315-321. https://doi.org/10.4067/s0718-40262018000300315

[13] Bichakjian, C.K., Olencki, T., Aasi, S.Z., Alam, M., Andersen, J.S., Berg, D., et al. (2016) Basal Cell Skin Cancer, Version 1.2016, NCCN Clinical Practice Guidelines in Oncology. Journal of the National Comprehensive Cancer Network, 14, 574-597. https://doi.org/10.6004/jnccn.2016.0065 